\title{
Cost Effectiveness of Secukinumab for the Treatment of Active Ankylosing Spondylitis in the UK
}

\author{
Paul Emery ${ }^{1,2} \cdot$ Marjolijn Van Keep $^{3} \cdot$ Steve Beard $^{4} \cdot$ Chris Graham $^{5} \cdot$ LaStella Miles $^{5}$ • \\ Steffen Marc Jugl ${ }^{6} \cdot$ Praveen Gunda $^{7}$ - Anna Halliday ${ }^{8}$ Helena Marzo-Ortega ${ }^{1,2}$
}

Published online: 25 May 2018

(C) The Author(s) 2018

\begin{abstract}
Objective To determine the cost effectiveness of secukinumab, a fully human interleukin-17A inhibitor, for adults in the UK with active ankylosing spondylitis (AS) who have not responded adequately to previous treatment with conventional care (CC; biologic-naïve population) or previous biologic therapy (biologic-experienced population). Perspective and Setting UK National Health Service (NHS).

Methods The model was structured as a 3-month decision tree leading into a Markov model. Comparators were licensed tumour necrosis factor inhibitors (including
\end{abstract}

Electronic supplementary material The online version of this article (https://doi.org/10.1007/s40273-018-0675-9) contains supplementary material, which is available to authorized users.

Anna Halliday

anna.halliday@novartis.com

1 Leeds Institute of Rheumatic and Musculoskeletal Medicine, University of Leeds, Leeds, UK

2 NIHR Leeds Biomedical Research Centre, Leeds Teaching Hospitals NHS Trust, Leeds, UK

3 BresMed Netherlands BV, Utrecht, The Netherlands

4 BresMed, Sheffield, UK

5 RTI Health Solutions, Research Triangle Park, NC, USA

6 Novartis Pharma AG, Basel, Switzerland

7 Novartis Healthcare Private Limited, Hyderabad, India

8 Novartis Pharmaceuticals UK Ltd, Camberley, Surrey, UK available biosimilars) and $\mathrm{CC}$ in the biologic-naïve and biologic-experienced populations, respectively. Clinical parameters captured treatment response, short-term disease activity and patient functioning, as well as long-term structural disease progression. Utilities were derived from secukinumab trial data. List prices were used for all drugs. The cost year was 2017 and costs and outcomes were discounted at $3.5 \%$.

Results In the biologic-naïve population, secukinumab dominated adalimumab and certolizumab pegol. Incremental cost-effectiveness ratios (ICERs) versus other comparators were either below $£ 10,000$ per quality-adjusted life-year (QALY) gained or south-west ICERs that implied cost effectiveness of secukinumab. In biologicexperienced patients, the ICER for secukinumab versus CC was $£ 4927$ per QALY gained. Treatment response rates, short-term treatment effects, long-term radiographic progression and biologic acquisition costs were key model drivers. Scenario analysis found results to be robust to changes in model structural assumptions. Probabilistic analysis identified greater uncertainty in results in the biologic-naïve population.

Conclusions Even at list price, secukinumab appears to represent a cost-effective use of NHS resources for biologic-naïve and biologic-experienced patients with active AS. Further research on long-term radiographic progression outcomes would be valuable for future cost-effectiveness analyses in AS. 


\section{Key Points for Decision Makers}

Secukinumab at list price appears to represent a costeffective treatment option from the perspective of the UK National Health Service for patients with active ankylosing spondylitis, including both patients who are naïve to prior biologic therapy and those who have previously received such therapy.

Cost-effectiveness results were generally robust to exploration of uncertainty in sensitivity and scenario analysis. Assumptions around rates of withdrawal from therapy had notable impacts on incremental cost-effectiveness estimates for secukinumab versus some tumour necrosis factor inhibitors (TNFis).

Further data collection on comparative long-term radiographic progression outcomes with biologics, and on the effectiveness of TNFis in biologicexperienced patients, would be valuable to reduce uncertainty.

\section{Introduction}

Ankylosing spondylitis (AS) is a chronic, progressive, irreversible arthritic condition characterised by inflammation of the sacroiliac joint at the base of the spine [1]. There are an estimated 200,000 AS diagnoses in the UK [2]. AS is three times more common in men than women and, as diagnosis is usually before the age of 45 years, primarily affects a working-age population. The natural history of AS is of progressive, irreversible, long-term deterioration in patient functioning resulting from ongoing disease activity (i.e. inflammation) and progressive structural damage (i.e. radiographic disease). AS is also associated with an increased risk of mortality, which is relatively higher for males than females [3].

Initial treatment for patients with AS in the UK is nonsteroidal anti-inflammatory drugs (NSAIDs) alongside non-pharmacological interventions (e.g. physiotherapy) to help relieve pain and stiffness. Together, these constitute 'conventional care' (CC). However, there is little evidence that $\mathrm{CC}$ prevents long-term structural progression of AS and many patients do not respond adequately to this treatment. The introduction of biologic therapies has transformed the treatment pathway for patients with AS, as reflected in guidelines from the British Society for Rheumatology/British Health Professionals in Rheumatology (BSR/BHPR), which recommend initiation of biologic treatment for patients with disease activity despite standard therapy [4]. The first five licensed biologics for AS were all tumour necrosis factor inhibitors (TNFis): etanercept, adalimumab, infliximab, golimumab, and certolizumab pegol. All five TNFis have received a positive recommendation from the National Institute for Health and Care Excellence (NICE) for the treatment of patients with severe active AS whose disease has responded inadequately to, or who cannot tolerate, NSAIDs [5]. Guidelines note the effectiveness of these therapies in reducing disease activity and spinal pain, but also acknowledge that evidence for impact of these therapies on radiographic disease progression is limited [4].

More recently, secukinumab, a fully human biologic therapy targeting interleukin (IL)-17A, has been licensed and recommended by NICE and the Scottish Medicines Consortium (SMC) for patients with an inadequate response to NSAIDs or TNFis, thus providing a novel mechanism of action for patients [6, 7]. Two phase III trials (MEASURE 1, MEASURE 2) demonstrated the efficacy and safety of secukinumab in patients with an inadequate response to $\mathrm{CC}$ who had not received a TNFi previously (hereafter referred to as 'biologic-naïve' patients) and in patients who had previously received a TNFi but withdrew from this therapy due to lack of efficacy or adverse events (hereafter referred to as 'biologic-experienced' patients) [8].

This research investigated the cost effectiveness of secukinumab for the treatment of active AS from the perspective of the UK National Health Service (NHS).

\section{Methods}

\subsection{Population, Interventions and Comparators}

The economic evaluation considered two distinct subpopulations of patients with active AS: (1) biologic-naïve patients; and (2) biologic-experienced patients. These two subpopulations align with the clinical subgroups explored in the MEASURE 1 and MEASURE 2 studies of secukinumab.

The patient population was defined based on patient characteristics from MEASURE 2 (average age 43.30 years; average weight $81.34 \mathrm{~kg}$; proportion of males 69.9\%). Baseline Bath Ankylosing Spondylitis Disease Activity Index (BASDAI) and Bath Ankylosing Spondylitis Functional Index (BASFI) scores were also taken from the MEASURE 2 study (see Sect. 2.3).

Secukinumab was modelled as the $150 \mathrm{mg}$ dose administered subcutaneously at weeks $0,1,2$ and 3 , followed by monthly maintenance dosing starting at week 4 , in line with the licensed posology. The relevant 
comparators to secukinumab in the biologic-naïve and biologic-experienced populations were reflective of clinical practice in the UK NHS, taking into consideration the availability of clinical data to allow robust economic evaluation. For the biologic-naïve population, this represented the five licensed and NICE/SMC-approved TNFis: etanercept, adalimumab, infliximab, golimumab, and certolizumab pegol (all at licensed doses). For two biologics (etanercept, infliximab), biosimilars are available in the UK and were included in the analysis as stand-alone comparators in addition to the originator products. Equal efficacy of biosimilar and originator products was assumed.

For the biologic-experienced population, the comparator in the base-case analysis was CC. Although AS treatment guidelines recommend sequential treatment with a subsequent TNFi after inefficacy or adverse events with the initial biologic treatment, a paucity of clinical data for use of comparator TNFis in the biologic-experienced population means that any economic analysis of sequential treatment would require unsupported assumptions regarding effectiveness of TNFis in biologic-experienced patients, and therefore lack robustness. Consideration of TNFis as comparators to secukinumab in the biologic-experienced population was therefore explored only as a scenario analysis.

\subsection{Model Structure}

The structure, inputs and assumptions for the model were informed by evidence from systematic literature reviews (SLRs) for relevant economic evaluations and studies reporting utility and cost/resource use data (see electronic supplementary material [ESM]). The model was developed based on the modelling framework used in previously published cost-effectiveness analyses of biologics for the treatment of AS, notably the York model [5, 9]. A cohort was modelled to initially enter a decision-tree model to determine response to treatment at 3 months, followed by entry into a Markov state-transition model comprised of three health states for maintenance treatment, $\mathrm{CC}$ and death (Fig. 1). The model was constructed in Microsoft Excel ${ }^{\circledR}$ (Microsoft Corporation, Redmond, WA, USA).

Treatment response was assessed at 3 months. This is in line with the earliest timepoint for assessment recommended in the latest treatment guidelines from the BSR/ BCHP, and the timepoint for assessment specified in the NICE guidance for TNFis $[4,5]$. The BSR/BCHP guidelines define response as a reduction in the BASDAI of $\geq 2$ units and $\mathrm{a} \geq 2 \mathrm{~cm}$ reduction in the spinal pain visual analogue scale (VAS); however, this response definition is not routinely measured in clinical trials [4]. Therefore, BASDAI 50 (50\% reduction in BASDAI score from baseline), as a readily available outcome that has been utilised in previous economic evaluations, was used to define response [9].

Patients classified as responders entered the Markov model in the maintenance treatment health state and were assumed to continue their initial biologic treatment until withdrawal due to lack of efficacy or adverse events. Nonresponders were assumed to discontinue their initial biologic therapy at 3 months. In the base case, these patients entered the Markov model in the $\mathrm{CC}$ health state and were modelled to receive $\mathrm{CC}$ until death, with no option to return to treatment with biologic therapy. In clinical practice, patients who withdraw from their initial biologic therapy may instead switch to a sequential biologic treatment [4]. This sequential biologic treatment was modelled as a scenario analysis due to lack of comparator data in biologic-experienced populations.

Successive 3-month cycles in the Markov model tracked disease progression through BASDAI score (reflecting disease activity) and BASFI score (reflecting changes to patient functioning). Disease-related costs and patient utility were linked to these long-term clinical outcomes to determine accrued costs and health benefits over the modelled time horizon. A 40-year time horizon was used to represent a lifetime time horizon, reflecting the chronic nature of the condition and treatment. Alternative time horizons were explored in scenario analyses.

\subsection{Modelling of Health Outcomes}

\subsubsection{Treatment Response}

An SLR was performed to identify clinical efficacy and safety outcomes, including BASDAI 50, for secukinumab and TNFis in both biologic-naïve and biologic-experienced populations [6]. This identified the MEASURE 1 and MEASURE 2 studies of secukinumab. The MEASURE 1 study used a non-licensed intravenous loading regimen and was therefore not used to inform clinical inputs in the basecase model, with the exception of withdrawal rates and utilities. Published BASDAI 50 scores were identified for all comparator TNFis in the biologic-naïve population; in the biologic-experienced population no comparator data were identified.

In the biologic-naïve population, BASDAI 50 model inputs were informed by a network meta-analysis (NMA) of BASDAI 50 scores, with the timepoint of BASDAI 50 score taken as the primary endpoint of the relevant trial, provided this was between weeks 12 and 16. Full details of the methods of the NMA have been published elsewhere [6]. In the biologic-experienced population, BASDAI 50 response rates for secukinumab and $\mathrm{CC}$ were taken directly from the secukinumab $150 \mathrm{mg}$ and placebo arms, respectively, of the MEASURE 2 study. Concomitant 
Fig. 1 Model structure.

a Decision-tree model structure. Responders were those patients who achieved a BASDAI 50 response at 3 months. b Markov model structure. The three-state Markov model depicted in the upper panel was used in the base-case analysis. The model structure allowing movement to a second three-state Markov model via a second decision tree (lower panel) was applied only in the scenario analysis in the biologic-naïve population in which sequencing of biologic therapies was explored. BASDAI Bath Ankylosing Spondylitis Disease Activity Index, $C C$ conventional care (a)

BASDAI 50

response

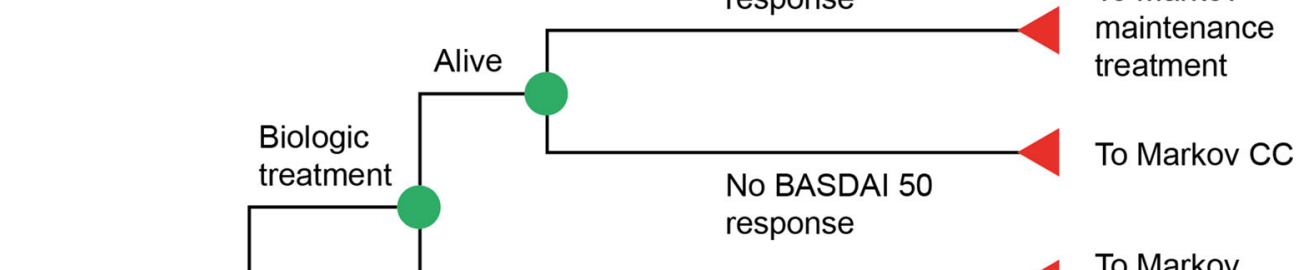

Dead
To Markov death

To Markov CC

(b)

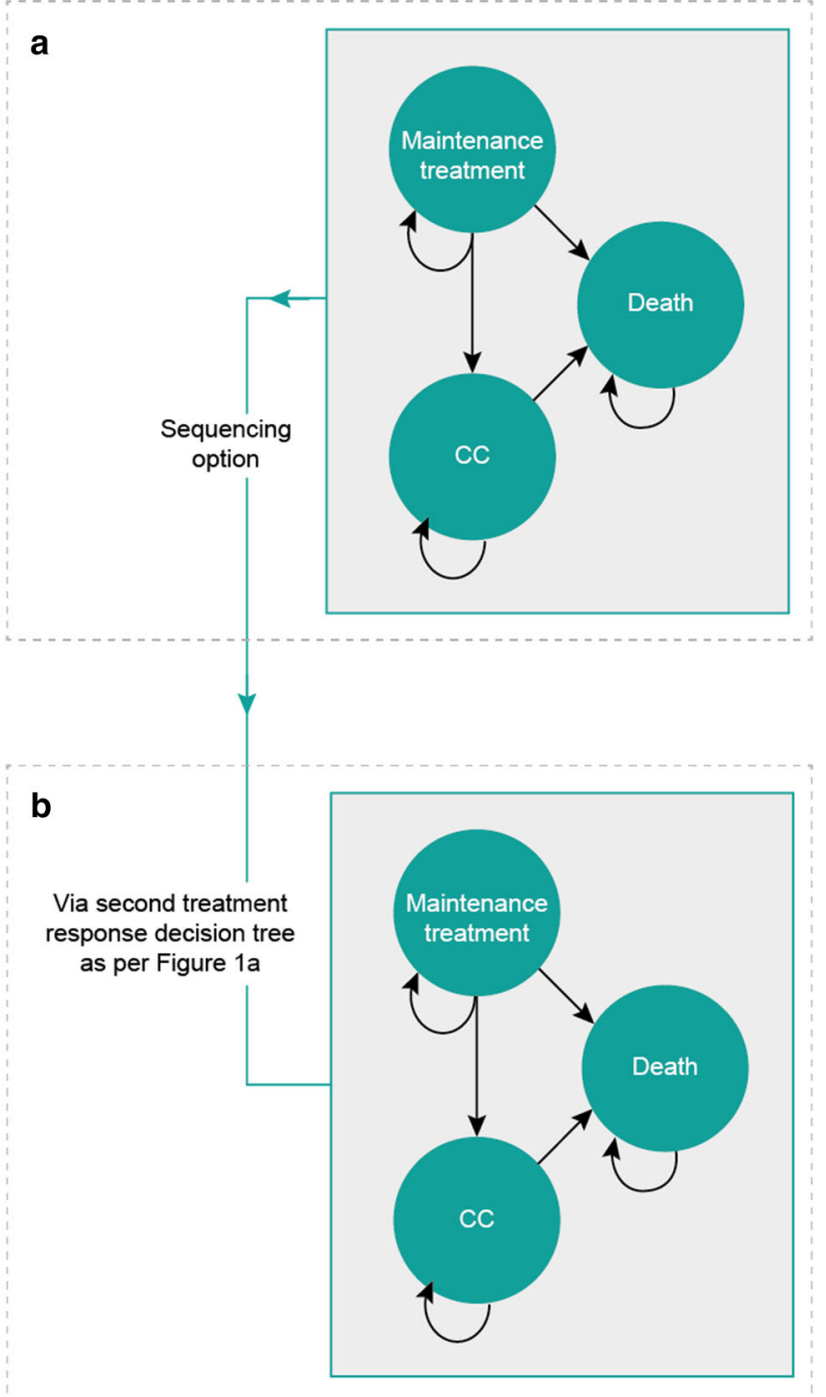


medications such as NSAIDs and physiotherapy were permitted in MEASURE 2, supporting the use of the placebo arm as a proxy to UK CC. BASDAI 50 response rates for the base-case analyses in the two populations are presented in ESM Table 4.

In the absence of efficacy data for TNFis in biologicexperienced patients, the sequencing scenario analyses in this population assumed the same placebo-adjusted relative reduction in response rate for the biologic-experienced population versus the biologic-naïve population, across all biologics, as observed in MEASURE 2 (37.6\%; derivation provided in ESM Table 5).

\subsubsection{Short-Term Health Outcomes}

Short-term health effects over the initial 12-week treatment period were captured by BASDAI and BASFI scores to reflect the impact of treatment on disease activity and patient functioning. BASDAI and BASFI scores at week 12 and beyond are conditional upon whether or not the patient responds to treatment [10]. As such, baseline and change from baseline BASDAI and BASFI scores were made conditional on BASDAI 50 response at 12 weeks using data from the active treatment arms of MEASURE 2 for secukinumab, ATLAS for adalimumab, and GO-RAISE for golimumab [5]. For all other comparators, conditional data were unavailable and estimates were based on the average ratio of responder to non-responder mean changes from baseline in each outcome at 12 weeks across the aforementioned sources [9]. These proportional changes for responders versus non-responders were then applied to absolute mean changes in BASDAI and BASFI at 12 weeks from the NMA, based on the proportion of responders. Conditional baseline and week 12 change from baseline BASDAI and BASFI data are provided in ESM Table 6.

\subsubsection{Long-Term Health Outcomes}

In addition to short-term effects on BASDAI and BASFI scores, the model captured the impact of treatment on longterm disease progression.

For BASDAI scores, conditional changes from baseline at week 12 were assumed to be maintained while patients remained in the maintenance treatment health state. Upon discontinuation of biologic therapy, BASDAI score was assumed to rebound to baseline.

Patients with AS experience progressive deterioration of function over time, dependent on the extent of disease activity and radiographic progression. This was captured as long-term progression in BASFI score. As BASDAI score was assumed constant in the long-term, natural progression of BASFI score was modelled as dependent on radiographic progression only (measured by the modified Stoke Ankylosing Spondylitis Spinal Score [mSASSS]) using the following equation: annual rate of BASFI change $=$ annual rate of mSASSS change $\times$ BASFI change with a 1-unit change in mSASSS. Consistent with the York model, the independent effect of a 1-unit change in mSASSS on BASFI scores was modelled by the multivariate relationship reported by Landewe et al. (mean 0.057; standard error 0.0049), and the annual rate of mSASSS change was taken as $1.440[11,12]$.

This rate of 1.440 represented the natural disease progression, and was applied for the CC arm under the assumption that $\mathrm{CC}$ had no impact on long-term radiographic progression. The treatment effect of biologics on slowing the rate of BASFI progression was assumed to start immediately on treatment initiation and was taken from the study by Haroon et al., which reported a relative rate of mSASSS change of 0.42 for patients receiving versus not receiving TNFis [13]. This was applied to all biologics, including secukinumab. However, it should be noted that this study included TNFis only. Although radiographic outcomes were not collected in MEASURE 2, secukinumab has demonstrated efficacy on radiographic progression outcomes in the MEASURE 1 study, with a mean change in mSASSS from baseline to week 104 of 0.30 for patients treated with secukinumab $150 \mathrm{mg}$ [14]. The basecase may therefore underestimate the impact of secukinumab in slowing radiographic progression, and a scenario analysis explored the application of an alternative relative rate of annual mSASSS change of 0.15 , based on the MEASURE 1 study, for patients treated with secukinumab. BASFI scores were assumed to return to baseline upon withdrawal of biologic therapy.

\subsubsection{Withdrawal of Biologic Therapy}

Annual withdrawal rates, which were converted to 3-month (per cycle) probabilities of withdrawal, are reported in ESM Table 7. The same annual withdrawal rate (11.0\%) was assumed for all TNFis in all years of the model, consistent with the York model [9]. For secukinumab, the withdrawal rates were derived directly from the pooled MEASURE 2 and MEASURE 1 studies (15.2\% in year 1 , $6.0 \%$ in all subsequent years). Separate scenario analyses explored the impact of applying withdrawal rates from the MEASURE 2 study alone for secukinumab, applying the $11.0 \%$ annual withdrawal rate to all treatments including secukinumab, and applying individual withdrawal rates to all treatments based on clinical trial data. 


\subsubsection{Adverse Events}

One adverse event (serious infections) was included in the model, with the probability of serious infection in each 3-month cycle based on naive trial data for each intervention (ESM Table 7). This adverse event was selected due to the increased risk of infection with biologic therapies targeting immune pathways, such as TNF $\alpha$ or IL-17A $[15,16]$. Five percent of serious infections were assumed to be cases of tuberculosis, which were modelled to have higher costs per event than other serious infections (see Sect. 2.5).

\subsubsection{Mortality}

Baseline mortality in the model was determined using mortality rates from the general population life tables, adjusted for sex-specific relative risks of death for patients with AS (males 1.63; females 1.38) consistent with the York model in AS [3, 9, 17].

\subsection{Utility Inputs}

Previous analyses have modelled patient health-related quality of life in AS to be dependent on BASDAI, BASFI, age and sex via regression models. As the model captured BASDAI and BASFI scores over time for patients remaining in the maintenance treatment health state versus those in the CC health state, this evaluation was similarly able to model health state utility using a regression model approach. The following utility algorithm, derived from patient-level data from the MEASURE 1 and MEASURE 2 trials, was utilised:

$$
\begin{aligned}
\text { Linear: Utility }= & 0.9610-0.0442 \times \mathrm{BASDAI}-0.0330 \\
& \times \mathrm{BASFI}-0.0111 \times \operatorname{Sex}[1=\text { male }, 0 \\
& =\text { female }]+0.0005 \times \text { Age } .
\end{aligned}
$$

\subsection{Cost and Resource Use Inputs}

The analysis was conducted from the perspective of the UK NHS, including only direct healthcare costs: drug acquisition costs (at list price in the base case), administration and monitoring costs, disease management costs and costs related to adverse events. The cost year of the analysis was 2017. Full cost and resource use inputs are provided in ESM Table 8.

\subsection{Model Outcomes}

Model outcomes included the total cost and quality-adjusted life-years (QALYs) accrued over the time horizon of the model, both discounted at a rate of $3.5 \%$ per year as per standard practice for UK cost-effectiveness analyses [18]. A half-cycle correction was applied to all outcomes. Cost effectiveness was assessed in terms of the incremental costeffectiveness ratio (ICER).

\section{Results}

\subsection{Base-Case Results}

In the biologic-naïve population, secukinumab dominated adalimumab and certolizumab pegol (Table 1a). ICERs versus all other comparators were either below $£ 10,000$ per QALY gained, or south-west ICERs that implied cost effectiveness of secukinumab. Fully incremental analysis found all interventions other than secukinumab, etanercept (biosimilar) and infliximab (biosimilar) to be dominated or extendedly dominated. The resulting ICER for secukinumab versus etanercept (biosimilar) was $£ 7524$ per QALY gained, while the ICER for infliximab (biosimilar) versus secukinumab was $£ 657,820$ per QALY gained.

In the biologic-experienced population, secukinumab was associated with a QALY gain of 1.018 compared with $\mathrm{CC}$, at increased costs of $£ 5014$ over the model time horizon (ICER of $£ 4927$ per QALY gained) (Table 1b).

\subsection{Sensitivity Analyses}

One-way sensitivity analyses (OWSA) were conducted to determine the key drivers of cost-effectiveness results separately for the biologic-naïve and biologic-experienced populations (see ESM Table 10 for details of the upper and lower values applied). Results were expressed in terms of net monetary benefit (NMB) valuing a single QALY at $£ 30,000$; dominance in some comparisons rendered the ICER measure uninformative for OWSA. Parameters associated with treatment response rates, short-term treatment effects, long-term radiographic progression and biologic acquisition costs were among the key model drivers in both populations (ESM Figs. 3 and 4).

Probabilistic sensitivity analyses (PSA) were conducted, varying model parameters simultaneously over 1000 simulations (ICERs were stable at this number of iterations). Point estimates for model parameters were derived from appropriate distributions using means and standard errors. For the biologic-naïve population, the PSA conservatively included the biosimilar versions of etanercept and infliximab, and not their originator products, as it was considered illogical to potentially observe iterations in which stochastic variation resulted in differing effectiveness of biosimilar and originator versions. Probabilistic results in both populations were broadly consistent with those from the deterministic base-case analysis and were associated 
Table 1 Base-case deterministic cost-effectiveness results (pairwise comparisons of secukinumab vs. each comparator and fully incremental analysis)

\begin{tabular}{|c|c|c|c|c|c|c|}
\hline Intervention & $\begin{array}{l}\text { Total } \\
\text { costs }\end{array}$ & $\begin{array}{l}\text { Total } \\
\text { QALYs }\end{array}$ & $\begin{array}{l}\text { Incremental } \\
\text { costs }\end{array}$ & $\begin{array}{l}\text { Incremental } \\
\text { QALYs }\end{array}$ & $\begin{array}{l}\text { ICER ( } £ \text { per QALY), } \\
\text { pairwise }\end{array}$ & $\begin{array}{l}\text { ICER ( } £ \text { per QALY), fully incremental } \\
\text { analysis }^{\mathrm{a}}\end{array}$ \\
\hline
\end{tabular}

(a) Biologic-naïve

$\begin{array}{lllllll}\begin{array}{l}\text { SEC (at list } \\ \text { price) }\end{array} & £ 124,064 & 8.833 & & & & £ 7524 \\ \text { ADA } & £ 127,962 & 8.680 & -£ 3898 & 0.152 & \text { SEC dominates } & \text { DEC dominates } \\ \begin{array}{l}\text { CZP (at list } \\ \text { price) }\end{array} & £ 125,995 & 8.741 & -£ 1931 & 0.092 & \text { Dominated } \\ \begin{array}{l}\text { ETN } \\ \text { (originator) }\end{array} & £ 122,927 & 8.414 & £ 1136 & 0.419 & £ 2712 & \text { Dominated } \\ \begin{array}{l}\text { ETN } \\ \text { (biosimilar) }\end{array} & £ 120,911 & 8.414 & £ 3152 & 0.419 & £ 7524 & - \\ \begin{array}{l}\text { GOL (at list } \\ \text { price) }\end{array} & £ 129,941 & 8.836 & -£ 5877 & -0.004 & £ 1,594,503^{\mathrm{b}} & \text { Extendedly dominated } \\ \begin{array}{l}\text { INF } \\ \text { (originator) }\end{array} & £ 145,170 & 8.859 & -£ 21,107 & -0.026 & £ 818,873^{\mathrm{b}} & \text { Dominated } \\ \begin{array}{l}\text { INF } \\ \text { (biosimilar) }\end{array} & £ 141,019 & 8.859 & -£ 16,955 & -0.026 & £ 657,820^{\mathrm{b}} & £ 657,820\end{array}$

\begin{tabular}{|c|c|c|c|c|c|}
\hline Intervention & Total costs & Total QALYs & Incremental costs & Incremental QALYs & ICER ( $£$ per QALY) \\
\hline \multicolumn{6}{|c|}{ (b) Biologic-experienced } \\
\hline $\mathrm{CC}$ & $£ 122,858$ & 7.264 & & & \\
\hline SEC (at list price) & $£ 127,872$ & 8.282 & $£ 5014$ & 1.018 & $£ 4927$ \\
\hline
\end{tabular}

$A D A$ adalimumab, $C C$ conventional care, $C Z P$ certolizumab pegol, ETN etanercept, GOL golimumab, ICER incremental cost-effectiveness ratio, $I N F$ infliximab, $Q A L Y$ quality-adjusted life-year, $S E C$ secukinumab

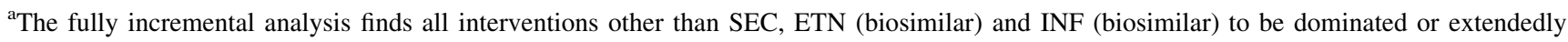
dominated. The ICER for SEC vs. ETN (biosimilar) was $£ 7524$, and the ICER for INF (biosimilar) vs. SEC was $£ 657,820$

${ }^{b}$ ICERs for SEC vs. the comparators that are marked with an asterisk represent ICERs in the south-west quadrant of the cost-effectiveness plane (negative incremental costs and negative incremental QALYs with SEC). Therefore, the ICER is a positive value and should be interpreted as the cost savings per QALY foregone with SEC vs. the comparator

with limited uncertainty (Table 2; ESM Figs. 5 and 6). The probability of secukinumab having the highest NMB in the biologic-naïve and biologic-experienced populations was 52.10 and $99.70 \%$, respectively, when one QALY was valued at $£ 30,000$ (Fig. 2).

\subsection{Scenario Analyses}

Key assumptions and areas of structural uncertainty in the model were explored through scenario analyses. There are no published comparative data of secukinumab versus TNFis for radiographic progression outcomes from which to draw robust scientific conclusions regarding comparative efficacy. However, in the MEASURE 1 study, mean $\pm \mathrm{s}-$ tandard deviation change in mSASSS from baseline to week 104 was $0.30 \pm 1.93$ for patients who received the $150 \mathrm{mg}$ maintenance dose of secukinumab. In contrast, previously published collated estimates of 2-year mSASSS change from baseline across TNFis ranged between 0.8 and
$1.0[9,14]$. Thus, assuming a slower rate of radiographic progression with secukinumab is a clinically realistic scenario, and an important one given the influence that the annual rate of change in the mSASSS parameter has on model results. This scenario resulted in improved cost effectiveness of secukinumab across all comparisons (Table 3).

Results from all scenario analyses are presented in Table 3 (biologic-naïve) and ESM Tables 11 and 12 (biologic-experienced). Cost-effectiveness conclusions were robust to scenario analysis; scenarios exploring alternative withdrawal rate assumptions were found to have the most notable impact on results.

\subsection{Model Validation}

Quality control for model internal validity was performed through independent review of the model by a different health economist to those responsible for initial 
Table 2 Probabilistic cost-effectiveness results (with pairwise comparison of secukinumab vs. each comparator) [average (95\% CIs)]

\begin{tabular}{|c|c|c|c|c|c|}
\hline Intervention & Mean total costs & Mean total QALYs & Mean incremental costs & $\begin{array}{l}\text { Mean incremental } \\
\text { QALYs }\end{array}$ & $\begin{array}{l}\text { Mean ICER }(£ \text { per } \\
\text { QALY })^{\mathrm{a}}\end{array}$ \\
\hline \multicolumn{6}{|c|}{ (a) Biologic-naïve } \\
\hline $\begin{array}{l}\text { SEC (at list } \\
\text { price) }\end{array}$ & $\begin{array}{l}£ 127,477(£ 125,448, \\
£ 129,506)\end{array}$ & $9.539(9.47,9.61)$ & & & \\
\hline ADA & $\begin{array}{l}£ 130,703(£ 128,688, \\
£ 132,719)\end{array}$ & $9.385(9.328,9.443)$ & $\begin{array}{l}-£ 3226(-£ 3722,- \\
£ 2730)\end{array}$ & $0.154(0.118,0.190)$ & SEC dominates \\
\hline $\begin{array}{l}\text { CZP (at list } \\
\text { price) }\end{array}$ & $\begin{array}{l}£ 129,102(£ 127,059, \\
£ 131,146)\end{array}$ & $9.430(9.371,9.489)$ & $\begin{array}{l}-£ 1625(-£ 2171,- \\
£ 1080)\end{array}$ & $0.109(0.07,0.148)$ & SEC dominates \\
\hline $\begin{array}{l}\text { ETN } \\
\text { (biosimilar) }\end{array}$ & $\begin{array}{l}£ 124,844(£ 122,744, \\
£ 126,943)\end{array}$ & $9.145(9.083,9.206)$ & $£ 2633(£ 2066, £ 3200)$ & $0.395(0.355,0.434)$ & $£ 6674$ \\
\hline $\begin{array}{l}\text { GOL (at list } \\
\text { price) }\end{array}$ & $\begin{array}{l}£ 133,782(£ 131,734, \\
£ 135,830)\end{array}$ & $9.522(9.462,9.581)$ & $\begin{array}{l}-£ 6305(-£ 6883,- \\
£ 5728)\end{array}$ & $\begin{array}{l}0.017(-0.021 \\
0.056)\end{array}$ & SEC dominates \\
\hline $\begin{array}{l}\text { INF } \\
\text { (biosimilar) }\end{array}$ & $\begin{array}{l}£ 145,078(£ 142,991, \\
£ 147,165)\end{array}$ & $9.554(9.495,9.613)$ & $\begin{array}{c}-£ 17,601(-£ 18,278,- \\
£ 16,925)\end{array}$ & $\begin{array}{r}-0.015(-0.056 \\
0.026)\end{array}$ & $£ 1,196,581^{\mathrm{b}}$ \\
\hline \multicolumn{6}{|c|}{ (b) Biologic-experienced } \\
\hline $\mathrm{CC}$ & $\begin{array}{l}£ 128,445(£ 125,654, \\
£ 131,237)\end{array}$ & $7.959(7.901,8.017)$ & & & \\
\hline $\begin{array}{l}\text { SEC (at list } \\
\text { price) }\end{array}$ & $\begin{array}{l}£ 133,144(£ 130,732, \\
£ 135,557)\end{array}$ & $8.967(8.906,9.028)$ & $£ 4699(£ 4119, £ 5279)$ & $1.008(0.986,1.031)$ & $£ 4660$ \\
\hline
\end{tabular}

$A D A$ adalimumab, $C C$ conventional care, $C I s$ confidence intervals, $C Z P$ certolizumab pegol, ETN etanercept, $G O L$ golimumab, ICER incremental cost-effectiveness ratio, INF infliximab, $Q A L Y$ quality-adjusted life-year, SEC secukinumab

${ }^{\mathrm{a}} 95 \%$ CIs are not provided for ICERs due to difficulty in interpretation of CIs where ICERs from probabilistic simulations span quadrants of the cost-effectiveness plane

${ }^{b}$ ICERs for SEC vs. the comparators that are marked with an asterisk represent ICERs in the south-west quadrant of the cost-effectiveness plane (negative incremental costs and negative incremental QALYs with SEC). Therefore, the ICER is a positive value and should be interpreted as the cost savings per QALY foregone with SEC vs. the comparator

construction of the model. Cross-validation of the model was performed through comparison of modelled total costs with those of the York model, which represented the most recent and relevant cost-effectiveness analysis for this population [9]. External validation was assessed through comparison of model-predicted BASDAI and BASFI outcomes with data from the BSR Biologics Register in AS (BSRBR-AS). Results of validation are provided in ESM Table 13.

\section{Discussion}

Secukinumab is the first licensed biologic for AS to target a novel molecule (IL-17A), and therefore the cost-effectiveness analysis presented here should be of interest to clinicians and commissioners in the UK NHS. Based on this analysis, secukinumab appears to represent a cost-effective intervention for the treatment of biologic-naïve and biologic-experienced patients with AS. Furthermore, secukinumab is available to the UK NHS with a confidential discount on the list price as part of a patient access scheme (PAS), which would further improve the cost effectiveness of secukinumab relative to the results presented in this current study.

A key strength of this analysis is the use of an SLR to identify clinical data to inform the model [19]. This review identified several high-quality trials that provide evidence in the biologic-naïve population across all therapies included in the analysis.

The analysis also benefits from the availability of patient-level data from MEASURE 2. This permitted determination of BASDAI and BASFI scores conditional upon response status, which is important given evidence for differential clinical outcomes between responders and non-responders into the longer-term [10]. Conversely, the analysis is limited by a lack of equivalent patient-level data for all comparator therapies, meaning the analysis relied on an assumption that the conditional data that are available (for secukinumab, adalimumab and golimumab) are applicable to other TNFi comparators.

One limitation of the analysis is that the SLR did not identify data for comparator therapies in the biologic-experienced population, precluding their inclusion as comparators in the base-case analysis for the biologicexperienced population. Therefore, the base-case 

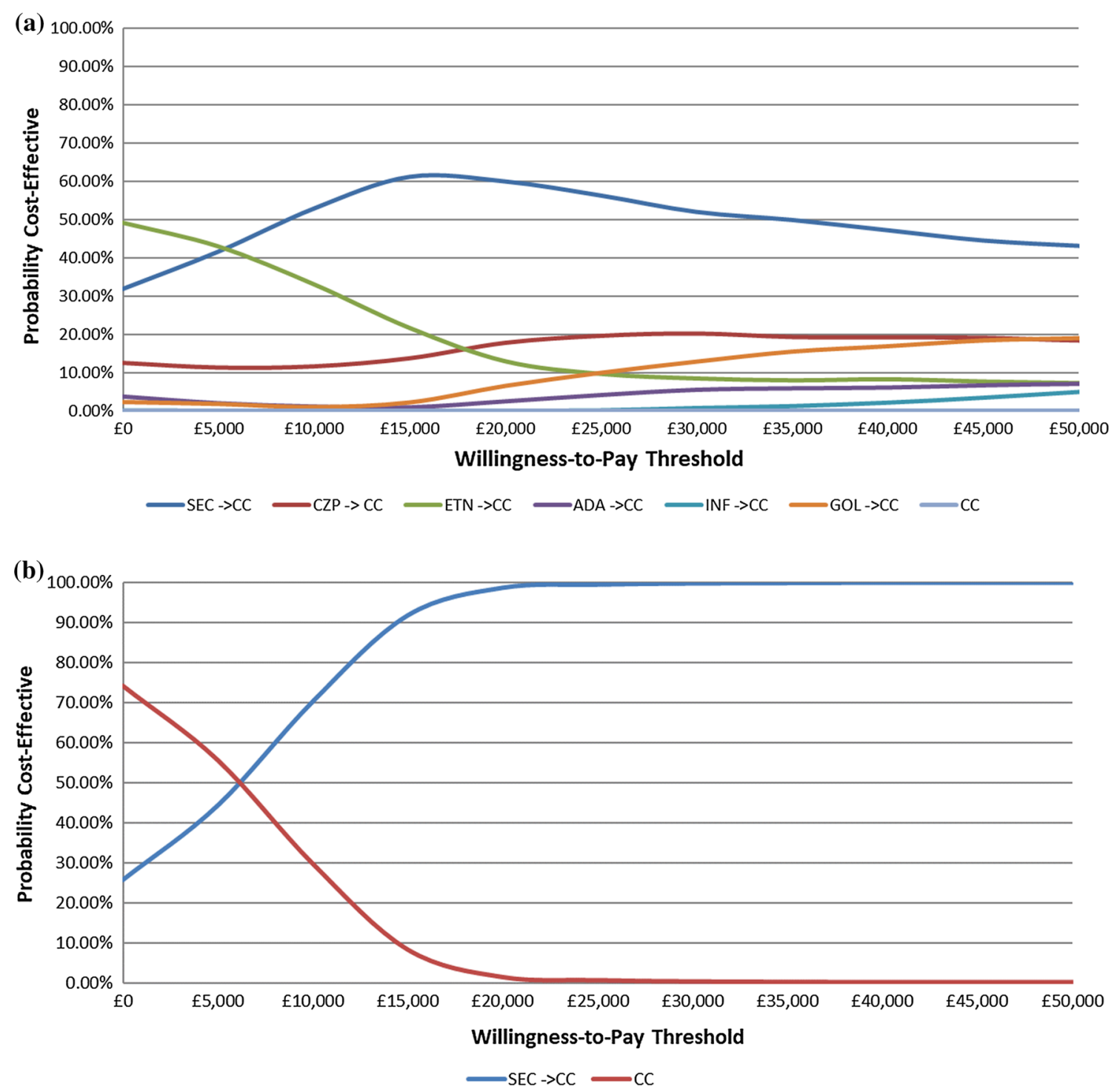

Fig. 2 Probabilistic results—cost-effectiveness acceptability curves. a Biologic-naïve population (all comparators). b Biologic-experienced population (vs. CC). $A D A$ adalimumab, $C C$ conventional care,

comparison (versus CC) may not fully represent UK clinical practice as it is likely clinicians would prescribe a second biologic following an inadequate response to the first [4].

An additional limitation with regard to the generalisability of the analysis to UK clinical practice relates to treatment response criteria. BSR guidelines previously defined treatment response as either a $50 \%$ reduction from baseline in the BASDAI or a $\geq 2$-unit drop in BASDAI total score from baseline and $\mathrm{a} \geq 2 \mathrm{~cm}$ reduction in spinal pain VAS [20]. The latest BSR/BHPR guidelines omit the BASDAI 50 component [4]. In contrast, the criterion for treatment response in our economic analysis was achievement of a BASDAI 50. Previous research has indicated the influence of the definition of response on the proportion of
CZP certolizumab pegol, ETN etanercept, GOL golimumab, INF infliximab, SEC secukinumab

responders and on the longer-term clinical outcomes of those classed as responders versus non-responders, and therefore this discrepancy represents an important limitation [21]. However, the use of the BASDAI 50 response reflects the primacy with which this outcome measure is used in clinical trials of therapies for AS, and hence the data available for modelling. Previous economic evaluations in AS have similarly defined response using BASDAI 50 [9].

Finally, the relative responder rates applied in the analysis are based on an NMA considering secukinumab 16-week data versus comparator TNFi 12-week data (14week data for golimumab), which may represent a source of bias towards secukinumab. However, this approach reflected primary outcome timepoints of the relevant trials 
Table 3 Scenario analyses in the biologic-naïve population - ICERs for secukinumab (at list price) versus all comparators

\begin{tabular}{|c|c|c|c|c|c|c|c|c|c|}
\hline \multirow[t]{2}{*}{ \# } & \multirow{2}{*}{$\begin{array}{l}\text { Variable/assumption } \\
\text { explored (base-case } \\
\text { setting) } \\
\text { Base case }\end{array}$} & \multirow[t]{2}{*}{ Scenario } & \multirow{2}{*}{$\begin{array}{l}\text { ADA } \\
\text { SEC } \\
\text { dominates }\end{array}$} & \multirow{2}{*}{$\begin{array}{l}\text { CZP (at list } \\
\text { price) } \\
\text { SEC } \\
\text { dominates }\end{array}$} & \multirow{2}{*}{$\begin{array}{l}\text { ETN } \\
\text { (originator) } \\
£ 2712\end{array}$} & \multirow{2}{*}{$\begin{array}{l}\text { ETN } \\
\text { (biosimilar) } \\
£ 7524\end{array}$} & \multirow{2}{*}{$\begin{array}{l}\text { GOL (at list } \\
\text { price) } \\
£ 1,594,503^{\mathrm{a}}\end{array}$} & \multirow{2}{*}{$\begin{array}{l}\text { INF } \\
\text { (originator) } \\
£ 818,873^{\mathrm{a}}\end{array}$} & \multirow{2}{*}{$\begin{array}{l}\text { INF } \\
\text { (biosimilar) } \\
£ 657,820^{\mathrm{a}}\end{array}$} \\
\hline & & & & & & & & & \\
\hline 1 & $\begin{array}{l}\text { Relative rate of } \\
\text { radiographic } \\
\text { progression } \\
\text { (change in } \\
\text { mSASSS) for SEC } \\
(0.42, \text { same as } \\
\text { TNFis) }\end{array}$ & $\begin{array}{l}0.15 \text {, lower } \\
\text { than TNFis }\end{array}$ & $\begin{array}{l}\text { SEC } \\
\text { dominates }\end{array}$ & $\begin{array}{l}\text { SEC } \\
\text { dominates }\end{array}$ & $£ 278$ & $£ 4675$ & $\begin{array}{l}\text { SEC } \\
\text { dominates }\end{array}$ & $\begin{array}{l}\text { SEC } \\
\text { dominates }\end{array}$ & $\begin{array}{l}\text { SEC } \\
\text { dominates }\end{array}$ \\
\hline $2 \mathrm{a}$ & $\begin{array}{l}\text { Time horizon } \\
\text { (40 years) }\end{array}$ & 20 years & $\begin{array}{l}\text { SEC } \\
\text { dominates }\end{array}$ & $\begin{array}{l}\text { SEC } \\
\text { dominates }\end{array}$ & $£ 2051$ & $£ 8226$ & $£ 75,207^{\mathrm{a}}$ & $£ 195,542^{\mathrm{a}}$ & $£ 158,379^{\mathrm{a}}$ \\
\hline $2 b$ & & 58 years & $\begin{array}{l}\text { SEC } \\
\text { dominates }\end{array}$ & $\begin{array}{l}\text { SEC } \\
\text { dominates }\end{array}$ & $£ 2581$ & $£ 7337$ & $\begin{array}{l}\text { SEC } \\
\text { dominates }\end{array}$ & $£ 990,934^{\mathrm{a}}$ & $£ 796,179^{\mathrm{a}}$ \\
\hline 3 & $\begin{array}{l}\text { BASFI rebound } \\
\text { (equal to initial } \\
\text { gain) }\end{array}$ & $\begin{array}{l}\text { Equal to } \\
\text { natural } \\
\text { history upon } \\
\text { withdrawal } \\
\text { of treatment }\end{array}$ & $\begin{array}{l}\text { SEC } \\
\text { dominates }\end{array}$ & $\begin{array}{l}\text { SEC } \\
\text { dominates }\end{array}$ & $\begin{array}{l}\text { SEC } \\
\text { dominates }\end{array}$ & $£ 3407$ & $\begin{array}{l}\text { SEC } \\
\text { dominates }\end{array}$ & $\begin{array}{l}\text { SEC } \\
\text { dominates }\end{array}$ & $\begin{array}{l}\text { SEC } \\
\text { dominates }\end{array}$ \\
\hline $4 a$ & $\begin{array}{l}\text { Treatment } \\
\text { withdrawal } \\
\text { probabilities } \\
\text { (SEC: pooled } \\
\text { MEASURE } 2 \text { and }\end{array}$ & $\begin{array}{l}\text { SEC: from } \\
\text { MEASURE } \\
2 \text { alone; } \\
\text { TNFis: from } \\
\text { York model }\end{array}$ & $£ 3715$ & $£ 6965$ & $£ 7751$ & $£ 9764$ & $£ 1300$ & $\begin{array}{l}\text { SEC } \\
\text { dominates }\end{array}$ & $\begin{array}{l}\text { SEC } \\
\text { dominates }\end{array}$ \\
\hline $4 b$ & $\begin{array}{l}\text { MEASURE 1; } \\
\text { TNFis: from York } \\
\text { model) }\end{array}$ & $\begin{array}{l}\text { York model } \\
\text { withdrawal } \\
(11.0 \%) \text { for } \\
\text { all } \\
\text { treatments, } \\
\text { including } \\
\text { SEC }\end{array}$ & $£ 61,134^{\mathrm{a}}$ & $£ 28,334^{\mathrm{a}}$ & $\begin{array}{l}\text { SEC } \\
\text { dominates }\end{array}$ & $£ 1159$ & $£ 32,962^{\mathrm{a}}$ & $£ 82,862^{\mathrm{a}}$ & $£ 68,578^{\mathrm{a}}$ \\
\hline $4 \mathrm{c}$ & & $\begin{array}{l}\text { Individual trial } \\
\text { probabilities } \\
\text { for all } \\
\text { treatments }\end{array}$ & $\begin{array}{l}\text { SEC } \\
\text { dominates }\end{array}$ & $\begin{array}{l}\text { SEC } \\
\text { dominates }\end{array}$ & $£ 10,200$ & $£ 11,452$ & $£ 35,461^{\mathrm{a}}$ & $\begin{array}{l}\text { SEC } \\
\text { dominates }\end{array}$ & $\begin{array}{l}\text { SEC } \\
\text { dominates }\end{array}$ \\
\hline 5 & $\begin{array}{l}\text { Response definition } \\
\text { (BASDAI 50) }\end{array}$ & $\begin{array}{l}\text { BASDAI } 50 \text { or } \\
\text { 2-point } \\
\text { decline in } \\
\text { BASDAI }\end{array}$ & $\begin{array}{l}\text { SEC } \\
\text { dominates }\end{array}$ & $\begin{array}{l}\text { SEC } \\
\text { dominates }\end{array}$ & $£ 2213$ & $£ 7631$ & $£ 5,205,547^{\mathrm{a}}$ & $£ 145,023^{\mathrm{a}}$ & $£ 116,504^{\mathrm{a}}$ \\
\hline $6 a$ & $\begin{array}{l}\text { Utility model } \\
\text { (MEASURE } 1 \text { and } \\
\text { MEASURE 2) }\end{array}$ & $\begin{array}{l}\text { Alternative } \\
\text { published } \\
\text { utility } \\
\text { model: } \\
\text { Wailoo et al. } \\
\text { [23] }\end{array}$ & $\begin{array}{l}\text { SEC } \\
\text { dominates }\end{array}$ & $\begin{array}{l}\text { SEC } \\
\text { dominates }\end{array}$ & $£ 2622$ & $£ 7274$ & $\begin{array}{l}\text { SEC } \\
\text { dominates }\end{array}$ & $\begin{array}{l}\text { SEC } \\
\text { dominates }\end{array}$ & $\begin{array}{l}\text { SEC } \\
\text { dominates }\end{array}$ \\
\hline $6 b$ & & $\begin{array}{l}\text { Alternative } \\
\text { published } \\
\text { utility } \\
\text { model: } \\
\text { McLeod } \\
\text { et al. [24] }\end{array}$ & $\begin{array}{l}\text { SEC } \\
\text { dominates }\end{array}$ & $\begin{array}{l}\text { SEC } \\
\text { dominates }\end{array}$ & $£ 2971$ & $£ 8242$ & $£ 3,314,513^{\mathrm{a}}$ & $£ 1,277,544^{\mathrm{a}}$ & $£ 1,026,280^{\mathrm{a}}$ \\
\hline 7 & $\begin{array}{l}\text { List price used for } \\
\mathrm{CZP} \text { and GOL }\end{array}$ & $\begin{array}{l}\text { Publicly } \\
\text { available } \\
\text { PAS } \\
\text { incorporated } \\
\text { for CZP and } \\
\text { GOL }\end{array}$ & $\begin{array}{l}\text { SEC } \\
\text { dominates }\end{array}$ & $£ 4367$ & $£ 2712$ & $£ 7524$ & $£ 500,376^{\mathrm{a}}$ & $£ 818,873^{\mathrm{a}}$ & $£ 657,820^{\mathrm{a}}$ \\
\hline
\end{tabular}


Table 3 continued

\begin{tabular}{|c|c|c|c|c|c|c|c|c|c|}
\hline \multirow[t]{2}{*}{ \# } & $\begin{array}{l}\text { Variable/assumption } \\
\text { explored (base-case } \\
\text { setting) }\end{array}$ & Scenario & ADA & $\begin{array}{l}\text { CZP (at list } \\
\text { price) }\end{array}$ & $\begin{array}{l}\text { ETN } \\
\text { (originator) }\end{array}$ & $\begin{array}{l}\text { ETN } \\
\text { (biosimilar) }\end{array}$ & $\begin{array}{l}\text { GOL (at list } \\
\text { price) }\end{array}$ & $\begin{array}{l}\text { INF } \\
\text { (originator) }\end{array}$ & $\begin{array}{l}\text { INF } \\
\text { (biosimilar) }\end{array}$ \\
\hline & Base case & & $\begin{array}{l}\text { SEC } \\
\text { dominates }\end{array}$ & $\begin{array}{l}\text { SEC } \\
\text { dominates }\end{array}$ & $£ 2712$ & $£ 7524$ & $£ 1,594,503^{\mathrm{a}}$ & $£ 818,873^{\mathrm{a}}$ & $£ 657,820^{\mathrm{a}}$ \\
\hline 8 & $\begin{array}{l}\text { No sequential } \\
\text { treatment with } \\
\text { biologics }\end{array}$ & $\begin{array}{l}\text { Sequential } \\
\text { treatment } \\
\text { with } \\
\text { biologics }\end{array}$ & $\begin{array}{l}\text { SEC } \\
\text { dominates }\end{array}$ & $\begin{array}{l}\text { SEC } \\
\text { dominates }\end{array}$ & $£ 27$ & $£ 5100$ & $£ 392,434^{\mathrm{a}}$ & $£ 754,370^{\mathrm{a}}$ & $£ 609,172^{\mathrm{a}}$ \\
\hline
\end{tabular}

ADA adalimumab, BASDAI Bath Ankylosing Spondylitis Disease Activity Index, BASFI Bath Ankylosing Spondylitis Functional Index, CZP certolizumab pegol, ETN etanercept, GOL golimumab, ICER incremental cost-effectiveness ratio, INF infliximab, mSASSS modified Stoke Ankylosing Spondylitis Spinal Score, PAS patient access scheme, QALYs quality-adjusted life-years, SEC secukinumab, TNFi tumour necrosis factor inhibitor

${ }^{a}$ ICERs for SEC versus the comparators that are marked with an asterisk represent ICERs in the south-west quadrant of the cost-effectiveness plane (negative incremental costs and negative incremental QALYs with SEC). Therefore, the ICER is a positive value and should be interpreted as the cost savings per QALY foregone with SEC vs. the comparator

and also the specified timepoint of assessment for $\mathrm{TNFi}$ therapies in NICE guidance [5, 6].

An important feature of the analysis is the modelling of long-term treatment effects on radiographic progression. For patients remaining on biologic therapy, this treatment effect is modelled beyond the length of available follow-up data for secukinumab or comparators, representing a source of uncertainty. An assumption of equivalent treatment effect on radiographic progression among TNFis would seem reasonable, given the shared mechanism of action. The model input value of 0.42 for the relative rate of mSASSS change with TNFis is based on empirical results from a study of TNFis, and this value was similarly applied as a class-effect assumption for TNFis in the York model $[9,13]$. In contrast, secukinumab possesses a different mechanism of action, and hence such an assumption may have less face validity, particularly in light of the mSASSS outcomes with secukinumab previously discussed.

There are clear areas where further research would benefit the analysis. First, availability of comparator data to allow definitions of treatment response to be aligned to those used by the BSR/BHPR would improve generalisability. Longer-term data for all treatments, and in particular comparative evidence on radiographic progression, also represent notable data gaps. Similarly, a lack of data on discontinuation beyond 2 years means that discontinuation rates applied for TNFis and secukinumab in the longterm are a key source of uncertainty that should be an area for further data collection. Finally, the scope of this research was to consider the perspective of the UK NHS; however, the academic literature also promotes the value of a societal perspective [22]. Given that AS is a disease of predominately working-age patients, there is a clear case for broadening the analysis to a societal perspective as an area of future research.

\section{Conclusions}

Secukinumab would appear to represent a cost-effective treatment option for patients with active AS, both for those patients who are biologic-naïve and those who are biologic-experienced. This research highlights a continued need for longer-term data on all biologic treatments in this indication to help inform future cost-effectiveness analyses.

Acknowledgements The authors acknowledge Costello Medical, UK, for writing and editorial assistance.

Author Contributions CG and LM were involved in model conceptualisation, design, development and validation, and provided technical input on the publication content. MVK and SB were involved in development and validation of the model and provided technical input on the publication content. SMJ and PG were involved in the model conceptualisation and provided input on the intellectual content of the publication. AH was involved in model validation and was responsible for defining and developing the intellectual content of the publication. HMO and PE provided clinical input on model design and validation, and on the publication content.

\section{Compliance with Ethical Standards}

Conflict of interest Marjolijn Van Keep, Steve Beard, Chris Graham and LaStella Miles declare they have no conflicts of interest. Marjolijn Van Keep and Steve Beard are employees of BresMed Health Solutions, and Chris Graham and La Stella Miles are employees of RTI Health Solutions; these organisations were contracted by Novartis Pharmaceuticals UK Ltd to undertake part of the work. Steffen Marc Jugl is an employee of Novartis Pharma AG, Basel, Switzerland, and owns stock and stock options in Novartis Pharma AG, Basel, Switzerland. Praveen Gunda is an employee of Novartis Healthcare Private Limited, Hyderabad, India. Anna Halliday is an employee of Novartis Pharmaceuticals UK Limited, Camberley, UK. Helena Marzo-Ortega has received grants from Janssen and Pfizer, and honoraria for speaking arrangements/advisory boards from AbbVie, Celgene, Janssen, Eli Lilly \& Co, MSD, Novartis, Pfizer and UCB. Paul Emery has undertaken clinical trials and provided expert 
advice to Pfizer, MSD, AbbVie, BMS, UCB, Roche, Novartis, Samsung, Sandoz and Eli Lilly \& Co.

Funding This study was funded by Novartis Pharmaceuticals UK Ltd, Camberley, UK.

Data availability statement The datasets used for the cost-effectiveness analysis are not publicly available, but may be available from the corresponding author on reasonable request.

Open Access This article is distributed under the terms of the Creative Commons Attribution-NonCommercial 4.0 International License (http://creativecommons.org/licenses/by-nc/4.0/), which permits any noncommercial use, distribution, and reproduction in any medium, provided you give appropriate credit to the original author(s) and the source, provide a link to the Creative Commons license, and indicate if changes were made.

\section{References}

1. McVeigh CM, Cairns AP. Diagnosis and management of ankylosing spondylitis. BMJ (Clin Res Ed). 2006;333(7568):581-5. https://doi.org/10.1136/bmj.38954.689583.DE.

2. National Ankylosing Spondylitis Society. Ankylosing spondylitis (AS) guidebook. London: National Ankylosing Spondylitis Society; 2012.

3. Bakland G, Gran JT, Nossent JC. Increased mortality in ankylosing spondylitis is related to disease activity. Ann Rheum Dis. 2011;70(11):1921-5. https://doi.org/10.1136/ard.2011.151191.

4. Hamilton L, Barkham N, Bhalla A, Brittain R, Cook D, Jones G, et al. BSR and BHPR guideline for the treatment of axial spondyloarthritis (including ankylosing spondylitis) with biologics. Rheumatology (Oxf, Engl). 2017;56(2):313-6. https://doi. org/10.1093/rheumatology/kew223.

5. National Institute for Health and Care Excellence. TNF-alpha inhibitors for ankylosing spondylitis and non-radiographic axial spondyloarthritis (TA383). Technology Appraisal Guidance. London: National Institute for Health and Care Excellence; 2016.

6. National Institute for Health and Care Excellence. Secukinumab for active ankylosing spondylitis after treatment with nonsteroidal anti-inflammatory drugs or TNF-alpha inhibitors (TA407). Technology Appraisal Guidance. London: National Institute for Health and Care Excellence; 2016.

7. Scottish Medicines Consortium. Advice ID 1159/16: secukinumab (Cosentyx). https://www.scottishmedicines.org.uk/SMC_ Advice/Advice/1159_16_secukinumab_Cosentyx_AS/secukinu mab_Cosentyx. Accessed 20 Sept 2017.

8. Baeten D, Sieper J, Braun J, Baraliakos X, Dougados M, Emery $\mathrm{P}$, et al. Secukinumab, an interleukin-17A inhibitor, in ankylosing spondylitis. N Engl J Med. 2015;373(26):2534-48. https://doi. org/10.1056/NEJMoa1505066.

9. Corbett M, Soares M, Jhuti G, Rice S, Spackman E, Sideris E, et al. Tumour necrosis factor-alpha inhibitors for ankylosing spondylitis and non-radiographic axial spondyloarthritis: a systematic review and economic evaluation. Health Technol Assess (Winch, Engl). 2016;20(9):1-334, v-vi. https://doi.org/10.3310/ hta20090.

10. Emery P, Halliday A, Jugl S, Mokashi S, Porter B, Martin R, et al., editors. Week 12 BASDAI 50 response predicts long-term efficacy of secukinumab in patients with active ankylosing spondylitis independent of previous TNFi exposure. Birmingham: British Society for Rheumatology; 2017.
11. Landewe R, Dougados M, Mielants H, van der Tempel H, van der Heijde D. Physical function in ankylosing spondylitis is independently determined by both disease activity and radiographic damage of the spine. Ann Rheum Dis. 2009;68(6):863-7. https:// doi.org/10.1136/ard.2008.091793.

12. Ramiro S, Stolwijk C, van Tubergen A, van der Heijde D, Dougados M, van den Bosch F, et al. Evolution of radiographic damage in ankylosing spondylitis: a 12 year prospective followup of the OASIS study. Ann Rheum Dis. 2015;74(1):52-9. https://doi.org/10.1136/annrheumdis-2013-204055.

13. Haroon N, Inman RD, Learch TJ, Weisman MH, Lee M, Rahbar $\mathrm{MH}$, et al. The impact of tumor necrosis factor alpha inhibitors on radiographic progression in ankylosing spondylitis. Arthritis Rheum. 2013;65(10):2645-54. https://doi.org/10.1002/art.38070.

14. Baeten D, Braun J, Sieper J, Dougados M, Deodhar AA, Baraliakos $\mathrm{X}$, et al. Secukinumab provides sustained improvements in the signs and symptoms of active ankylosing spondylitis: 2-year efficacy and safety results from a phase 3, randomized, double-blind, placebo-controlled trial [abstract]. Arthritis Rheumatol. 2015;67(suppl 10).

15. Singh JA, Wells GA, Christensen R, Tanjong Ghogomu E, Maxwell LJ, MacDonald JK, et al. Adverse effects of biologics: a network meta-analysis and Cochrane overview. Cochrane Database Syst Rev. 2011. https://doi.org/10.1002/14651858. cd008794.pub2.

16. European Medicines Agency (EMA). Cosentyx: EPAR—product information. http://www.ema.europa.eu/ema/index.jsp?curl= pages/medicines/human/medicines/003729/human_med_001832. jsp\&mid=WC0b01ac058001d124. Accessed 4 Jun 2017.

17. Office for National Statistics. National life tables: United Kingdom (2011-2013). https://www.ons.gov.uk/peoplepopulationand community/birthsdeathsandmarriages/lifeexpectancies/datasets/ nationallifetablesunitedkingdomreferencetables. Accessed 23 May 2017.

18. National Institute for Health and Care Excellence (NICE). PMG9: guide to the methods of technology appraisal-the reference case (2013). https://www.nice.org.uk/process/pmg9/ chapter/the-reference-case. Accessed 23 May 2017.

19. Drummond MF, Iglesias CP, Cooper NJ. Systematic reviews and economic evaluations conducted for the National Institute for Health and Clinical Excellence in the United Kingdom: a game of two halves? Int J Technol Assess Health Care. 2008;24(2):146-50. https://doi.org/10.1017/s0266462308080203.

20. Keat A, Barkham N, Bhalla A, Gaffney K, Marzo-Ortega H, Paul $\mathrm{S}$, et al. BSR guidelines for prescribing TNF-alpha blockers in adults with ankylosing spondylitis. Report of a Working Party of the British Society for Rheumatology. Rheumatology (Oxf, Engl). 2005;44(7):939-47. https://doi.org/10.1093/rheumatology/ keh669.

21. Marzo-Ortega H, Halliday A, Jugl S, Mokashi S, Porter B, Talloczy Z, et al., editors. E28-impact of alternative definitions of treatment response on long-term efficacy of secukinumab in tumour necrosis factor alpha-naïve patients with active ankylosing spondylitis. Birmingham: British Society for Rheumatology; 2017.

22. Sanders GD, Neumann PJ, Basu A, et al. Recommendations for conduct, methodological practices, and reporting of cost-effectiveness analyses: second panel on cost-effectiveness in health and medicine. JAMA. 2016;316(10):1093-103. https://doi.org/ 10.1001/jama.2016.12195.

23. Wailoo A, Hernandez M, Philips C, Brophy S, Siebert S. Modeling health state utility values in ankylosing spondylitis: comparisons of direct and indirect methods. Value Health J Int Soc Pharmacoecon Outcomes Res. 2015;18(4):425-31. https:// doi.org/10.1016/j.jval.2015.02.016. 
24. McLeod C, Bagust A, Boland A, Dagenais P, Dickson R, Dundar $\mathrm{Y}$, et al. Adalimumab, etanercept and infliximab for the treatment of ankylosing spondylitis: a systematic review and economic evaluation. Health Technol Assess 2007;11(28):1-158 (iii-iv).
(Winch, Engl). 